ORIGINAL ARTICLE

\title{
Fire fighter fatalities 1998-2001: overview with an emphasis on structure related traumatic fatalities
}

\author{
T K Hodous, T J Pizatella, R Braddee, D N Castillo
}

Injury Prevention 2004;10:222-226. doi: 10.1136/ip.2004.005348

See end of article for authors' affiliations

....................

Correspondence to: T J Pizatella, NIOSH, Division of Safety Research, 1095 Willowdale Road Morgantown, WV 26505, USA; tip2@cdc.gov

\begin{abstract}
Objective: To review the causes of all fire fighter line-of-duty-deaths from 1998 through 2001, and present recommendations for preventing fatalities within the specific subgroup of structure related events.

Methods: Fire fighter fatality data from the United States Fire Administration were reviewed and classified into three main categories of injury. Investigations conducted through the National Institute for Occupational Safety and Health (NIOSH) Fire Fighter Fatality Investigation and Prevention Program provided the basis for the recommendations presented in this paper.

Results: During the time period from 1998-2001, there were 410 line-of-duty deaths among fire fighters in the United States, excluding the 343 fire fighters who died at the World Trade Center on 11 September 2001. The 410 fatalities included 191 medical (non-traumatic) deaths (47\%), 75 motor vehicle related fatalities (18\%), and 144 other traumatic fatalities (35\%). The latter group included 68 fatalities that were associated with structures which commonly involved structural collapse, rapid fire progression, and trapped fire fighters.

Conclusions: Structural fires pose particular hazards to fire fighters. Additional efforts must be directed to more effectively use what we have learned through the NIOSH investigations and recommendations from published experts in the safety community, consensus standards, and national fire safety organizations to reduce fire fighter fatalities during structural fire fighting.
\end{abstract}

A ccording to data from the United States Fire Administration (USFA), during the period 1977 through 2002, there was an average of 115 fire fighter fatalities per year, not including the 343 fire fighters who died at the World Trade Center on 11 September 2001.' Over the last decade, there have also been approximately 90000 non-fatal fire fighter injuries annually, about half occurring at a fire scene. ${ }^{2}$ Fire fighters face many hazards, including physical stresses, ground and air transportation risks, as well as fire scene injury hazards that are specific to the fire fighting profession. Structural fires pose particular hazards to fire fighters from structural collapse or becoming lost or disoriented and unable to escape before running out of oxygen. For the period 1977 through 2000, the number of fire fighter deaths in structure fires declined 59\%; however, the rate of fire fighter deaths from traumatic injuries during structural fire fighting has actually increased over this same time period. ${ }^{3}$ Fahy reports that in the late 1970s, traumatic fire fighter deaths occurred at a rate of 1.8 deaths per 100000 structure fires; by the late 1990s, this rate had increased to 3.0 deaths per 100000 structure fires. ${ }^{3}$ Despite improvements in personal protective equipment and other new technologies developed for fire fighting, the profession remains one of the most hazardous. ${ }^{45}$

In 1998, Congress funded the National Institute for Occupational Safety and Health (NIOSH) to develop the Fire Fighter Fatality Investigation and Prevention Program (FFFIPP). The purpose of this program is to investigate lineof-duty-deaths of fire fighters in the United States, and provide recommendations to the fire community so that future incidents can be prevented*.

This paper reviews the major causes of fire fighter fatalities from 1998 through 2001. It then focuses on those fatalities that occurred during fire fighting activities in burning structures, and presents key prevention recommendations from NIOSH investigations specific to these events. The paper presents a four year synthesis of NIOSH recommendations for preventing fatalities during structural fire fighting.

\section{METHODS}

Fire fighter fatality data for this study came from the USFA annual summary of fire fighter line-of-duty-deaths. ${ }^{6-9}$ The USFA receives notification of and collects basic descriptive data on all fire fighter fatalities, including career and volunteer fire fighters.

Reports of investigations conducted through the NIOSH FFFIPP were also reviewed. ${ }^{10}$ NIOSH identifies fire fighter fatalities primarily through notification by the USFA, but may also include direct contact from a fire department in which a fatality occurred, or through news reports of a fire fighter's death. The NIOSH investigations involve site visits, including a review of available fatal incident records, interviews with involved fire fighting personnel, and review of operational procedures, so these investigations provide detailed information about the circumstances of each fatal event.

For this analysis, the circumstances of all fatalities were individually reviewed and classified by the authors into three main categories: medical, motor vehicle, or non-motor vehicle trauma. It should be noted that in a few cases, the exact circumstances of death even after investigation were not clear or involved a combination of factors. However, in this analysis, each fatality is only counted once. Because of these factors, and the summary categories used, small differences may be found when comparing the data in this paper with other fire fighter fatality tabulations.

A medical fatality was defined as an acute non-traumatic medical event (such as a myocardial infarction) that led to

Abbreviations: FFFIPP, Fire Fighter Fatality Investigation and Prevention Program; NIOSH, National Institute for Occupational Safety and Health; SOPs, standard operating procedures; USFA, United States Fire Administration

*Further information about the NIOSH FFFIPP, including all investigative reports, can be found on the NIOSH web page: http://www.cdc.gov/ niosh/firehome.html. 
Box 1: Volunteer fire fighter fatally injured in roof collapse

A 27 year old male volunteer fire captain was trapped in a roof collapse while fighting a structural fire in a church. The first arriving fire fighters observed smoke and fire coming from the rear of the church. After an initial size-up, the chief ordered a defensive attack at the rear of the structure. To control extension of the fire, the chief directed a hose line be taken into the church to conduct an offensive attack. The chief also directed fire fighters to check for fire extension in the attic area. A lieutenant observed no fire in the attic at this time and advised the captain. Smoke conditions within the church consisted of only a light haze. The captain and one fire fighter exited the church and advised the chief of conditions in the attic area. As the captain and chief were reentering the church to size-up interior conditions, without warning, the entire roof collapsed, trapping the captain under heavy, burning roof timbers.

Source: NIOSH FFFIPP, Report Number 99-04.

the fire fighter's death. Motor vehicle fatalities included deaths caused by injuries sustained in a crash as a driver or occupant of a moving fire truck or a personally owned vehicle when traveling related to fire fighter duties (either to or from an incident scene), or as an on-duty pedestrian struck by a motor vehicle. All other fatalities were grouped into a third category, non-motor vehicle trauma. The structure related fatalities were then further categorized as a subset of the non-motor vehicle trauma events. Information on potential interventions to prevent structure related fire fighter fatalities was synthesized from NIOSH investigative reports ${ }^{10}{ }^{11}$ that drew from published guidelines in the area of fire fighter safety. ${ }^{12-17}$

\section{RESULTS}

Table 1 presents a categorization of fire fighter fatalities from 1998 through 2001. The 191 medical deaths comprised the single largest group (47\% of the total); 171 (90\%) of these were due to myocardial infarctions, with most other deaths caused by stroke or a cardiac arrhythmia (in a fire fighter without coronary artery disease). It should be noted that most of these fatalities occurred at, soon after, or traveling to or from the fire scene, so that the physical and psychological stresses of fire fighting were considered significant contributing causes.

Motor vehicle fatalities constituted the second largest single cause of death ( 75 or $18 \%$ of the total). Twenty eight (37\%) of the 75 motor vehicle related deaths occurred in single-vehicle crashes, often involving loss of control at a road curve and subsequent fire truck rollover. Twenty four (32\%) of the motor
Table 2 Specific circumstances of non-motor vehicle traumatic fatalities, including those that were structure related

\begin{tabular}{lll}
\hline Specific circumstance & Total fatalities & Structure related \\
\hline Asphyxia/burn & 69 & 57 \\
Struck by/fall & 26 & 8 \\
Air transportation & 21 & 0 \\
Water related & 9 & 0 \\
Electrocution & 8 & 1 \\
Explosion & 6 & 2 \\
Violence (excluding & 5 & 0 \\
arson) & 144 & 68 \\
Totals & & \\
\hline
\end{tabular}

vehicle incidents occurred to fire fighters as pedestrians, often at the site of a prior motor vehicle crash.

The remaining 144 fatalities were due to varying types of traumatic events, but were not motor vehicle related. Table 2 presents the specific circumstances surrounding these nonmotor vehicle trauma fatalities, including those that were structure related. Because the catastrophic loss of 343 fire fighter lives on 11 September 2001 would substantially change typical patterns, these fatalities are not included in the analysis.

Within this general category of non-motor vehicle trauma, the most common (69 out of 144; 48\%) cause of death was asphyxiation or burns, followed by struck by/fall, and air transportation. Sixty eight of these 144 fatalities were structure related, with $57(83 \%)$ of the fatalities due to asphyxia/burn, and another eight (30\%) due to a struck by/ fall. Nearly all the air transportation deaths were related to wildland fire fighting efforts.

Of the 57 structure related fatalities that were categorized as asphyxia/burn, a building collapse resulted in 17 deaths (30\%); flashovert or rapid fire progression resulted in 15 deaths (26\%); a fire fighter becoming lost and/or running out of air resulted in nine of the deaths $(16 \%)$, with the remaining 16 either due to multiple factors or the specific cause was unclear. Eight fatalities were included in the struck by/fall category. Injury scenarios for these cases included fatal crushing injuries due either to a collapse of the structure onto the fire fighter, or falling through a floor or roof of a burning structure. The disintegration of the structure was commonly involved, with collapse of building components onto fire fighters (either inside or outside the structure), or fatal falls from or through floors or rooftops. Boxes 1 and 2 highlight two investigations from the NIOSH FFFIPP which illustrate the hazards fire fighters face while fighting structural fires.

${ }^{\dagger}$ Flashover is one form of rapid and potentially fatal fire progression that can create temperatures over $1000^{\circ} \mathrm{F}$.

Table 1 Fire fighter fatalities by year and category A

\begin{tabular}{lllll}
\hline & \multicolumn{3}{l}{ Category of fatality } & \\
\cline { 2 - 4 } Year & Medical & Motor vehicle & $\begin{array}{l}\text { Non-motor vehicle } \\
\text { trauma }\end{array}$ & Total \\
\hline 1998 & 43 & 20 & 31 & 94 \\
1999 & 59 & 19 & 34 & 112 \\
2000 & 45 & 20 & 37 & 102 \\
2001 & 44 & 16 & $42^{*}$ & $102^{*}$ \\
Totals (\%)* & $191(47)$ & $75(18)$ & $144(35)$ & $410(100)$ \\
\hline *The 343 fire fighter fatalities at the World & Trade Center disaster are not included in the totals and percentages \\
shown. & & & \\
\hline
\end{tabular}


Box 2: Career fire fighter dies in supermarket fire after running out of air

A 40 year old male career fire fighter died from carbon monoxide poisoning and thermal burns after running out of air and becoming disoriented while fighting a supermarket fire. The fire started near a dumpster on the exterior of the structure and extended through openings in the loading dock into the storage area and then into the main shopping area of the supermarket. The fire progressed to five alarms and involved more than 100 fire fighters. Conditions deteriorated as the structure began to fill with thick, black smoke, and the fire continued to intensify. The victim radioed to incident command that he was low on air, and then become disoriented in the confusing layout of the structure. After an extensive search and rescue effort, fire fighters located and removed the downed fire fighter from the structure and transported him to a local hospital where he was pronounced dead.

Source: NIOSH FFFIPP, Report Number 2001-13.

\section{NIOSH recommendations for structure related fire fighting}

NIOSH conducted an investigation of 58 (85\%) of the 68 fatal events that were structure related. In focusing on the structure related fatalities, it should be noted that the NIOSH recommendations are specific to the incidents studied; however, all of the investigations identified multiple contributing factors, and several general themes have developed. Box 3 provides key recommendations from past NIOSH investigations. ${ }^{111}$ On average, each investigative report had five different recommendations.

The recommendation for developing and implementing standard operating procedures (SOPs), which in some sense, could encompass essentially all of the recommendations, address a variety of issues. SOPs provide the primary basis for fire fighting activities at a scene, and are essential in ensuring

Box 3: Prevention recommendations included in NIOSH investigations of structure related

fatalities (in order of decreasing frequency of citation in NIOSH investigative reports)

(1) Develop, implement, and enforce standard operational procedures as related to structural fire fighting techniques and strategies.

(2) Provide adequate and continuous communication between the incident commander and interior fire fighting crews.

(3) Establish rapid intervention crews to respond immediately to emergencies on the fire scene.

(4) Ensure the proper use of personal alert safety system devices.

(5) Ensure that accountability for all fire personnel at the fire scene is maintained.

(6) Ensure that incident command conducts an initial size-up of the incident before initiating fire fighting efforts, and continuously assesses the risk versus gain of interior attack.

(7) Ensure that adequate numbers of staff are available to immediately respond to emergency incidents.

(8) Assign an incident safety officer, separate from the incident commander. fire fighter safety. Examples of SOPs for structural fire fighting include donning and checking for the proper operation of personal protective equipment; ensuring that all interior attack activities are conducted in full turnout gear, with personal alert safety system devices and self contained breathing apparatus on and charged; and defining procedures for conducting interior fire fighting activities. SOPs for an interior attack could consist of: fire fighters advancing one hoseline to the interior for a fast, offensive attack; conducting support activities, such as roof ventilation; completing a primary search; and advancing a second hoseline to the interior to back up the first hoseline.

Where possible, adequate and continuous communication on the scene should be provided through the use of portable radios to ensure the incident commander can communicate instructions to interior fire fighting crews, as well as changes in strategy and tactics during the course of the fireground attack. Portable radios also allow interior fire fighting crews to communicate changing conditions back to the incident commander for continual evaluation of the risk versus gain of maintaining an interior fire attack. Additionally, these communications help the incident commander identify the locations of interior fire fighting crews which assists in maintaining fire fighter accountability on the scene-a key function of incident command.

One of the most important aids for maintaining fire fighter accountability is the Incident Management System. This is a tool that defines the roles and responsibilities of all units responding to an incident. It enables the incident commander to have better control of the incident scene, and works on an understanding among fire fighting crews that the incident commander will be "standing back" from the incident, focusing on the entire scene, making decisions as conditions dictate.

Exterior and interior size-up provide the foundation for all subsequent operations, helping the incident commander to plan the initial attack. One of the most important size-up duties of the first-in officers is locating the fire and determining its severity. This information lays the foundation for the entire operation, helping to determine the number of fire fighters and the amount of apparatus and equipment needed to control the blaze. Size-up also assists in determining the most effective point of fire extinguishment and the most effective method of venting heat and smoke. As interior conditions change during the course of a fire, it is essential that this information be communicated back to the incident commander so that important decisions regarding the attack strategy or tactics can be made. For example, information communicated back to the incident commander could result in a decision to shift from an interior (offensive) attack to an exterior (defensive) attack, requiring an immediate evacuation of all fire fighters from a structure.

Other recommendations in addition to those identified in box 3 include the immediate use of an audible evacuation tone or alert when interior conditions become unsafe for fire fighters; appropriate and timely structure ventilation tactics, and the use of exit markers or other guides to help fire fighters escape a burning structure. For example, fire departments should consider using guide ropes (or tag lines) securely attached to permanent objects at entry portals to assist lost or disoriented fire fighters in emergency escape from smoke filled environments. Additionally, placing high intensity floodlights at entry portals may assist fire fighters in locating exits in emergency situations.

\section{DISCUSSION}

Most fire fighting SOPs involve, after an initial size-up and with adequate and capable resources, an offensive (interior) search and attack to locate and rescue possible civilians, 
better assess the fire and its origin, and to effectively provide fire suppression. ${ }^{13}{ }^{16} 17$ Particularly when civilians are known or thought to be inside a burning structure, fire fighters will take significant risks to themselves to save the lives of others. Accepting this approach, it then becomes a difficult matter to determine when the risk to a fire fighter outweighs the benefits of initiating or continuing an interior attack. Unfortunately, there are no absolutely reliable approaches here, and the NIOSH fatality investigations indicate that catastrophic conditions commonly developed with great rapidity in a number of the fatal fires. For example, in only $20 \%$ of the incidents investigated by NIOSH had the fire fighters begun an evacuation of the structure. The data reported in this analysis reinforce structural fire dangers which have been noted by experts for some years. ${ }^{12-14}$

To a large extent, a key problem is determining, in time for fire fighters to safely escape, when a catastrophic, life threatening event (such as major collapse, floor failure, or rapid fire progression) will occur. At present, there are no uniformly accurate assessment tools to make this determination, and incident commanders and fire fighters must often rely primarily on past experience and good judgment in deciding when to exit a burning structure. As well, there are many factors that can contribute to a structural collapse or rapid fire progression which make such assessments complex. These factors include the type of construction, age of the structure, presence of combustible materials, fire origin, and hidden fire in void spaces. ${ }^{11-13}$

It is important to note that the safety recommendations provided with this analysis are based primarily on recommendations from the NIOSH investigative reports which include reference to published experts in the safety community, consensus standards, and recommended procedures by national fire safety organizations. More quantitative data and intervention evaluation studies would significantly advance our understanding of the critical elements that lead to fire fighter fatalities in structure fires.

In addition, future improvements in the safety of fire fighters in burning buildings may come from improved training and technology. Training will help fire fighters better appreciate the unpredictability of some fires, their rapidity of progression, and early danger indicators. Improved technologies may be able to provide earlier warning signs, as well as improve communication, personal protective equipment, detection of hidden fires, location of downed fire fighters, and identification of egress paths for quicker escape.

\section{CONCLUSIONS}

Assessing the integrity of a burning structure, and its potential for collapse on the scene of a working fire, can be an exceedingly complex task as many factors can contribute to a structural collapse. There are no uniform assessment tools to accurately determine when a structure will collapse, thus, there are no hard and fast rules on when to exit a burning structure. Future technological innovations may provide the fire service with advanced tools to make better assessments on the fire scene. At present, however, additional efforts must be directed to more effectively use what we have learned through the NIOSH investigations and recommendations from published experts in the safety community, consensus standards, and national fire safety organizations within the fire service.

In order to effectively reduce the risk to fire fighters from structural collapse and other hazards, prevention efforts must include a comprehensive set of strategies (including those outlined in box 3 ) that are consistently implemented for each response. However, the decision to assess when the risk to fire fighters outweighs the benefits of initiating or maintaining an interior attack typically rests on the shoulders of the

\section{Key points}

- Although the number of fire fighter deaths in structure fires has declined over the last 20 years, the rate of fire fighter deaths from traumatic injuries during structural fire fighting has actually increased over this same time period.

- Structural fires pose particular hazards to fire fighters; fatalities while fighting structural fires typically involve structural collapse, rapid fire progression, and trapped fire fighters.

- Assessing the integrity of a burning structure is a complex task, and presents a difficult problem for the fire service in determining when a catastrophic, life threatening event, such as a major collapse, will occur; at present, there are no uniform assessment tools to assist incident commanders and fire fighters in accurately determining when to exit a burning structure before it collapses.

- In only $20 \%$ of the NIOSH investigations of fatalities due to structural fire fighting had fire fighters begun an evacuation before the structure collapsed.

- To reduce fire fighter fatalities during structural fire fighting, additional efforts must be directed to more effectively use what we have learned through the $\mathrm{NIOSH}$ fatality investigations and recommendations from published experts in the safety community, consensus standards, and national fire safety organizations.

- Additional training for incident commanders and fire fighters may enhance awareness of the hazards of structural fires and be useful in guiding critical decision making on the fire ground.

incident commander at the scene. Additional training for incident commanders and fire fighters may enhance awareness of the hazards of structural fires and be useful in guiding critical decision making on the fire ground.

\section{ACKNOWLEDGEMENTS}

The authors would like to acknowledge the continued cooperation of the United States Fire Administration and the National Fire Protection Association in providing data for use by the NIOSH FFFIPP. The authors would also like to acknowledge the numerous staff past and present from the NIOSH FFFIPP who conducted the fatality investigations that served as the basis for the recommendations presented in this paper.

\section{Authors' affiliations}

T K Hodous, T J Pizatella, R Braddee, D N Castillo, Division of Safety Research, National Institute for Occupational Safety and Health, Centers for Disease Control and Prevention

\section{REFERENCES}

1 United States Fire Administration. Firefighter fatalities in the United States in 2002. Emmitsburg, MD: Federal Emergency Management Agency, July 2003, FA-260).

2 Karter MJ, Badger SG. US firefighter injuries of 2000. National Fire Protection Association Journal November/December 2001:49-54.

3 Fahy RF. US fire service fatalities in structure fires, 1977-2000. National Fire Protection Association Journal July/August, 2001:1-10.

4 Fosbroke DE, Kisner SM, Myers JR. Working lifetime risk of occupational fatal injury. Am J Ind Med 1997;31:459-67.

5 Clarke C, Zak MJ. Fatalities to law enforcement officers and firefighters, 1992-1997. Compensation and Working Conditions 1999;4(No 2):3-7. 
6 United States Fire Administration. Firefighter fatalities in the United States in 1998. Emmitsburg, MD: Federal Emergency Management Agency, August 1999.

7 United States Fire Administration. Firefighter fatalities in the United States in 1999. Emmitsburg, MD: Federal Emergency Management Agency, July 2000, FA-211)

8 United States Fire Administration. Firefighter fatalities in the United States in 2000. Emmitsburg, MD: Federal Emergency Management Agency, August 2001, FA-215.

9 United States Fire Administration. Firefighter fatalities in the United States in 2001. Emmitsburg, MD: Federal Emergency Management Agency, August 2002, FA-237.

10 National Institute for Occupational Safety and Health. Firefighter fatality reports, 1998-2001 (individual reports available from NIOSH at: http:// www.cdc.gov/niosh/firehome.html).
11 National Institute for Occupational Safety and Health. ALERT: preventing injuries and deaths of fire fighters due to structural collapse. Cincinnati, $\mathrm{OH}$ : injuries and deaths of fire fighters due to structura
DHHS (NIOSH) Publication No 99-146, 1999.

12 Brannigan FL. Building construction for the fire service. 3rd Ed. Quincy, MA: National Fire Protection Association, 1999.

13 Dunn V. Safety and survival on the fireground. Saddle Brook, NJ: Fire Engineering Books \& Videos, 1992.

14 Karter MJ. Patterns of firefighter fireground injuries. Quincy, MA: National Fire Protection Association, 2000

15 National Fire Protection Association. NFPA 1500, standard on fire department occupational safety and health program. Quincy, MA: NFPA, 2000.

16 Brunicini AV. Fire command. Quincy, MA: National Fire Protection Association, 1985.

17 Carter W, Childress D, Coleman RJ, et al. Firefighter's handbook. Albany, NY: Delmar Thompson Learning, 2000.

\section{LACUNAE}

\section{Japan wary of revolving doors}

utomatic revolving doors have become increasingly popular with Japanese architects. They help buildings efficiently regulate heat and air conditioning systems, they're easy to operate in high rise complexes that create gusty winds, and they lend an air of technological sophistication. But these days, most of the 466 automatic revolving doors in Japan are idle. The shutdown has occurred after the death this spring of a 6 year old boy who was crushed by a 1 ton revolving door at Roppongi Hills in Tokyo, a glitzy entertainment and business complex featuring a 54 story high rise. On March 26, Ryo Mizokawa removed his hand from his mother's grip and darted into the fast moving revolving door, his 44 inch $(110 \mathrm{~cm})$ frame just shy of the machine's infrared motion detectors. The automatic doors kept moving even after Ryo's head became caught between the door and frame. Ryo, an only child, and his mother were visiting the year old complex from the Osaka region. Public horror turned to outrage when it was disclosed that Ryo's death was the latest in a string of 32 other accidents in nine revolving doors at Roppongi Hills. Hospital treatment was required in 10 of the accidents. Automatic revolving doors have caused more than 270 accidents throughout Japan in the past several years, including 32 that resulted in broken bones, according to an April report by the government. Most of the automatic revolving doors at 294 locations in Japan-including those at Roppongi Hills, supermarkets, hotels, and a large number of hospitals-are closed pending results of a government study due by early July. The other doors have full time guards monitoring their use or have been converted into sliding doors.

Japan does not have official regulations regarding revolving doors. Accidents generally have been reported as routine mishaps. But the government has been aware of problems with the automatic doors since the mid-1990s. In 1996, government safety manuals advised builders that people with disabilities were vulnerable to mishaps when using the doors. By 2000, the government said children and senior citizens were particularly susceptible to injury from the doors. Last year, the government said the doors should not be used, but nothing was mandated or enforced.

The door at Roppongi Hills was typically large, about 10 feet wide, and could accommodate seven persons in each of its partitioned sections. Including the frame, the door weighed almost 3 tons. Tokyo police are investigating the parent company of the revolving door maker and the management firm at Roppongi Hills as part of a criminal probe into Ryo's death for possible professional negligence. Meanwhile, the revolving door has generated some macabre interest. It is blocked by blue safety tape and flanked by a small table covered with a white cloth that features a solemn note from the owner of the complex. The site is photographed frequently (from the Boston Globe, June 2004; submitted by Anara Guard). 